Article

\title{
Electroanalytical Performance of Nitrogen-Doped Graphene Films Processed in One Step by Pulsed Laser Deposition Directly Coupled with Thermal Annealing
}

\author{
Florent Bourquard ${ }^{1}$, Yannick Bleu ${ }^{1}{ }^{\circledR}$, Anne-Sophie Loir ${ }^{1}{ }^{\circledR}$, Borja Caja-Munoz ${ }^{2}$, José Avila ${ }^{2}$, \\ Maria-Carmen Asensio ${ }^{3}$, Gaëtan Raimondi ${ }^{4}$, Maryam Shokouhi ${ }^{4}$, Ilhem Rassas ${ }^{4}$, Carole Farre ${ }^{4}$, \\ Carole Chaix ${ }^{4}{ }^{\mathbb{D}}$, Vincent Barnier ${ }^{5}$, Nicole Jaffrezic-Renault $\left.{ }^{4}{ }^{(}\right)$, Florence Garrelie ${ }^{1}$ \\ and Christophe Donnet $1, * \mathbb{D}$ \\ 1 Laboratoire Hubert Curien, UMR 5516 CNRS, Université de Lyon, Université Jean Monnet, \\ F-42000 Saint-Étienne, France; Florent.Bourquard@univ-st-etienne.fr (F.B.); \\ yannick.bleu@univ-st-etienne.fr (Y.B.); Anne.Sophie.Loir@univ-st-etienne.fr (A.-S.L.); \\ Florence.Garrelie@univ-st-etienne.fr (F.G.) \\ 2 Synchrotron SOLEIL, Université Paris-Saclay, Saint Aubin, F-91192 Gif sur Yvette, France; \\ borja.caja-munoz@synchrotron-soleil.fr (B.C.-M.); jose.avila@synchrotron-soleil.fr (J.A.) \\ 3 Instituto de Ciencia de Materiales de Madrid, Sor Juana Inés de la Cruz, 328049 Madrid, Spain; \\ mc.asensio@csic.es \\ 4 Institut des Sciences Analytiques, UMR 5280 CNRS, Université de Lyon, Université Claude Bernard Lyon 1, \\ F-69100 Villeurbanne, France; gaetan.raimondi@isa-lyon.fr (G.R.); m.shokouhi89@gmail.com (M.S.); \\ ilhemras@hotmail.fr (I.R.); carole.farre@univ-lyon1.fr (C.F.); carole.chaix-bauvais@univ-lyon1.fr (C.C.); \\ Nicole.Jaffrezic@univ-lyon1.fr (N.J.-R.) \\ 5 Mines Saint-Etienne, Université de Lyon, UMR 5307 CNRS, Centre SMS, F-42023 Saint-Etienne, France; \\ barnier@emse.fr \\ * Correspondence: christophe.donnet@univ-st-etienne.fr
}

Received: 29 January 2019; Accepted: 20 February 2019; Published: 23 February 2019

check for updates

\begin{abstract}
Graphene-based materials are widely studied to enable significant improvements in electroanalytical devices requiring new generations of robust, sensitive and low-cost electrodes. In this paper, we present a direct one-step route to synthetize a functional nitrogen-doped graphene film onto a Ni-covered silicon electrode substrate heated at high temperature, by pulsed laser deposition of carbon in the presence of a surrounding nitrogen atmosphere, with no post-deposition transfer of the film. With the ferrocene methanol system, the functionalized electrode exhibits excellent reversibility, close to the theoretical value of $59 \mathrm{mV}$, and very high sensitivity to hydrogen peroxide oxidation. Our electroanalytical results were correlated with the composition and nanoarchitecture of the N-doped graphene film containing 1.75 at \% of nitrogen and identified as a few-layer defected and textured graphene film containing a balanced mixture of graphitic-N and pyrrolic-N chemical functions. The absence of nitrogen dopant in the graphene film considerably degraded some electroanalytical performances. Heat treatment extended beyond the high temperature graphene synthesis did not significantly improve any of the performances. This work contributes to a better understanding of the electrochemical mechanisms of doped graphene-based electrodes obtained by a direct and controlled synthesis process.
\end{abstract}

Keywords: graphene; nitrogen-doped graphene; pulse laser deposition; electrochemical analysis; oxygen peroxide oxidation 


\section{Introduction}

Graphene is considered to be a promising 2D material thanks to its unique versatile properties, in particular high thermal and electrical conductivity, with many potential applications as an electrode in chemistry and as an electrocatalyst in fuel cells, field emitters, batteries, supercapacitors, and sensors (for a review, see Reference [1]).

The structure and electronic properties of graphene can be tailored by heteroatom doping, in particular by incorporating nitrogen, thereby opening the band gap and transforming graphene into a semiconductor, as recently reviewed by Yadav et al. [2] and $\mathrm{Xu}$ et al. [3].

Some authors have studied the electrochemical properties of N-doped graphene (NG) in various experimental conditions. Wang et al. [4] obtained NG with a nitrogen content ranging between 0.11 and 1.35 at \%, by nitrogen plasma exposure of graphene prepared by chemical reduction of graphene oxide. The NG films exhibited consistent electrocatalytic activity for the reduction of hydrogen peroxide $\left(\mathrm{H}_{2} \mathrm{O}_{2}\right)$, as well as high sensitivity and selectivity for glucose biosensing. Shao et al. [5] compared the electroanalytical properties of NG electrode with pure graphene $(\mathrm{G})$ and $\mathrm{Pt} / \mathrm{C}$ electrode. Oxygen reduction reaction (ORR) overpotential is lower on NG than $\mathrm{G}$, meaning that $\mathrm{N}$ doping significantly increases the electrocatalytic activity of graphene towards ORR. Although the NG electrode exhibited a lower initial electrocatalytic activity than $\mathrm{Pt} / \mathrm{C}$, it was much more stable and durable, suggesting that it may be possible to replace expensive Pt with low-cost NG. Moreover, unlike Pt, ORR on NG was not influenced by fuel molecules, making NG in direct liquid fuel cells very promising. The overpotential during electrocatalytic $\mathrm{H}_{2} \mathrm{O}_{2}$ reduction was significantly reduced, and a well-defined and enhanced $\mathrm{H}_{2} \mathrm{O}_{2}$ reduction peak was observed around $-0.2 \mathrm{~V}$, demonstrating better NG electrocatalytic activity compared to undoped graphene for $\mathrm{H}_{2} \mathrm{O}_{2}$ sensing. Ruiyi et al. [6] incorporated nitrogen in multiple graphene aerogel/gold nanostars (N-doped MGA/GNS) and reported that such a sensor was more sensitive than that of all reported DNA sensors to date. Saengsookwaow et al. [7] showed that, during cyclic voltammetry, a screen-printed carbon electrode (SPCE) functionalized by NG/Polyvinylpyrrolidone PVP/Gold nanoparticles (AuNPs) increased the anodic peak current by a factor of 10 compared to unmodified SCPE, due to a significant improvement in the interfacial charge transfer. This type of electrode showed higher electrochemical sensitivity and electrocatalytic activity toward hydrazine oxidation, leading to successful determination of hydrazine content in fruit and vegetable samples. Recently, Li et al. [8] also studied SPCE functionalized by NG sheets (NGS) obtained from graphene oxide and reported consistent sensitivity, selectivity and stability (with less overpotential required for oxidation) for nicotine detection, including when the molecule was in urine and tobacco samples.

However, most previous studies were performed with NG synthetized using rather complex chemical routes, with limited control of the nitrogen concentration incorporated in the graphene network. Thus, the investigation of electrochemical properties of NG films obtained by more simple routes is still of great interest for the next generations of electrodes. In particular, synthesis of NG film in one step from a solid carbon source directly onto silicon electrodes has been less explored than NG films obtained by other routes, including CVD processes and various reduction processes of GO by thermal annealing, plasma treatment, hydrothermal or solvothermal reactions in the presence of a nitrogen precursor. In a previous paper [9], we reported on the performance of a graphene electrode processed in one step by pulsed laser deposition directly coupled with in situ thermal annealing (PLD-TA). The electrochemical behavior of the NG film was studied in the presence of the redox probe, ferrocene methanol, which was shown to be the most suitable for quantifying electron transfer with graphene. Cyclic voltammetry revealed excellent electrochemical kinetic and quasi-reversibility performances. The attachment of ethynyl aryl groups on the surface of the electrode was robust, paving the way for the specific attachment of molecules bearing an azide function using the click reaction.

Moving on from there, in the present study we investigated the electroanalytic performance of a NG-functionalized electrode obtained using the one-step PLD-TA process previously successfully used for the electroanalytical investigation of pure graphene film. In a recent review [10], we mentioned 
that only three papers reported on the synthesis of NG films from an amorphous nitrogenated carbon film (a-C:N) obtained by PLD. Kumar et al. [11] reported in situ growth of n-type NG films (2 at \% of nitrogen) by PLD performed at $973 \mathrm{~K}$, with an increase in electrical conductivity with increased nitrogen partial pressure. Ren et al. [12] used the same approach and obtained NG films (1.7 to 3.2 at \%) showing improved chemical enhancement for Raman analysis of absorbed Rhodamine 6G molecules, compared to pristine graphene. Recently, our group reported for the first time the synthesis of NG-doped few-layer graphene from a solid state nitrogen carbide (a-C:N film) synthetized by femtosecond pulse laser ablation [13]. We investigated the nanostructure and chemical composition of an NG film obtained by a vacuum thermal annealing at $780{ }^{\circ} \mathrm{C}$ of an a-C:N film previously deposited onto a $\mathrm{SiO}_{2}$ substrate and further covered by a Ni catalytic film (150 nm). Here we optimize the previous protocol to form the NG film directly by high temperature condensation of the laser-induced carbon plasma plume in the presence of nitrogen atmosphere, onto the Si electrode previously covered by a Ni catalytic film. The structure and composition of the NG film, compared to undoped ones, were investigated by Raman spectroscopy, X-ray photoelectron spectroscopy (XPS) and scanning electron microscopy (FEG-SEM). To show the interest of using NG film as an electrode for biological applications, its performance in the detection of hydrogen peroxide $\left(\mathrm{H}_{2} \mathrm{O}_{2}\right)$ was compared to that of graphene film. $\mathrm{H}_{2} \mathrm{O}_{2}$ is the product of the enzymatic detection of glucose in diabetes diagnosis and its electrochemical detection is implemented in a commercial glucometer. Moreover, $\mathrm{H}_{2} \mathrm{O}_{2}$ is involved in different signal transduction pathways and cell fate decisions. The "redox signaling" mechanism includes the $\mathrm{H}_{2} \mathrm{O}_{2}$-mediated reversible oxidation of redox sensitive cysteine residues in enzymes and transcription factors, thereby altering their activities. In comparison to normal cells, cancer cells are characterized by an increased $\mathrm{H}_{2} \mathrm{O}_{2}$ production rate and an impaired redox balance, thereby affecting the microenvironment as well as the antitumoral immune response [14]. There is consequently a strong demand for hydrogen peroxide detection in the cell environment.

\section{Materials and Methods}

\subsection{Graphene Film Synthesis and Characterization}

Figure 1 is a schematic diagram of NG film synthesis. Nickel film (150 nm thick) was deposited by thermal evaporation on the top of an n-doped silicon substrate, previously cleaned (in acetone then in ethanol and DI water baths) in a vacuum chamber pumped at a base pressure of $10^{-6} \mathrm{mbar}$. High purity (99.99\%) Ni was molten thermally in a tungsten nacelle and evaporated towards the substrate. The deposition rate was set at $1.5 \mathrm{~nm} / \mathrm{min}$ to minimize residual stress in the growing film, thereby limiting film delamination. The Ni/Si samples were introduced in the PLD chamber pumped at a base pressure of $10^{-6}$ mbar, annealed at $780^{\circ} \mathrm{C}$ for $30 \mathrm{~min}$ to increase the $\mathrm{Ni}$ grain size. While maintaining the temperature of $780{ }^{\circ} \mathrm{C}$, carbon was ablated from a high purity graphite $(99.9995 \%)$ target using a femtosecond laser (wavelength $=800 \mathrm{~nm}$; pulse width $=60 \mathrm{~ns}$, repetition rate $=1 \mathrm{kHz}$, energy density $=5 \mathrm{~J} / \mathrm{cm}^{2}$ ) at a temperature of $780{ }^{\circ} \mathrm{C}$. The $\mathrm{Ni} / \mathrm{Si}$ substrates were mounted on a sample holder placed at a distance of $36 \mathrm{~mm}$ from the graphite target. Nitrogen gas (99.9995\% purity) was introduced as a reactant gas in the vacuum chamber at a pressure of $10^{-1}$ mbar.

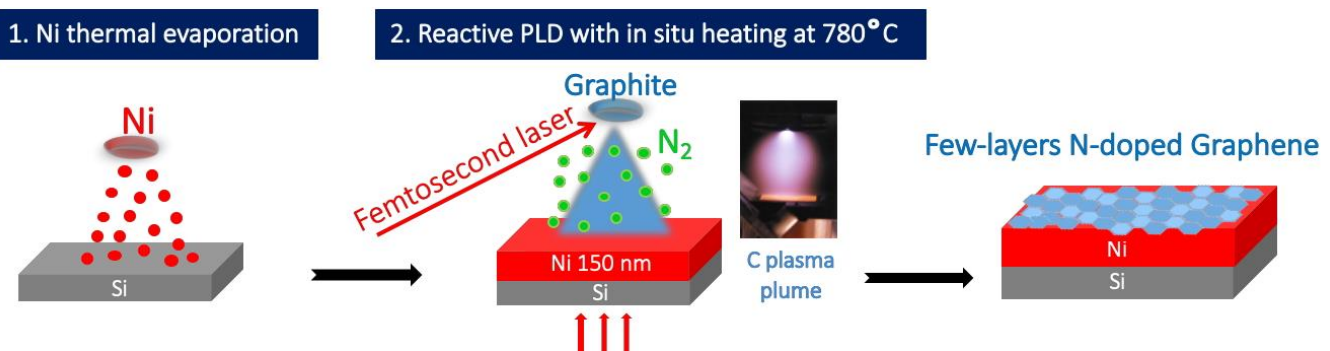

Figure 1. Synthesis of the N-doped graphene electrode. 
Undoped graphene films were also synthetized using the same protocol, but without introducing nitrogen gas during carbon ablation. The ablation time was adjusted to keep both carbon and nitrogenated carbon film thicknesses equal to $40 \mathrm{~nm}$. In some cases, the temperature of $780{ }^{\circ} \mathrm{C}$ was maintained for a defined period after deposition to observe the effect of longer heating periods. The procedure ended with natural cooling of the samples, before opening the vacuum chamber. In the present paper, we selected four deposition conditions to highlight the major effects due to nitrogen doping, compared to undoped films. The conditions are summarized in Table 1.

The morphology of the sample was observed using a field emission gun scanning electron microscope (FEG-SEM) Novananosem 200, (FEI, Hillsboro, OR, USA) operated at 15 kV. Micro-Raman analyses were performed using an Aramis spectrometer (Horiba Jobin Yvon, Gières, France), with $442 \mathrm{~nm}(2.81 \mathrm{eV})$ excitation laser focused through a $\times 100$ objective with high aperture, ensuring the micrometric resolution of the analysis, and allowing for precise Raman mapping of the samples.

Table 1. Specific deposition parameters of the graphene films.

\begin{tabular}{ccc}
\hline Graphene Films & $\begin{array}{c}\mathbf{N}_{\mathbf{2}} \text { Pressure during Deposition } \\
\text { at } \mathbf{7 8 0}{ }^{\circ} \mathbf{C}\end{array}$ & $\begin{array}{c}\text { Additional Period of Annealing at } \mathbf{7 8 0} \\
\text { after Deposition }\end{array}$ \\
\hline NG-0 & $10^{-1}$ mbar & No additional annealing \\
\hline NG-60 & $10^{-1} \mathrm{mbar}$ & $60 \mathrm{~min}$ \\
\hline G-60 & - & $60 \mathrm{~min}$ \\
\hline G-90 & - & $90 \mathrm{~min}$ \\
\hline
\end{tabular}

For each sample, $20 \times 20 \mu \mathrm{m}^{2}$ areas were scanned, recording a Raman spectrum every $2 \mu \mathrm{m}$ (giving a total of 100 spectra per scanned area). The laser power was kept below $3 \mathrm{~mW}$ to avoid damaging the surface of the film. Raman components were associated with a Lorentzian fit, safe for the asymmetric $G$ peak, which was fitted using a Breit-Wigner-Fano function. A custom fitting function was computed for all recorded spectra, and a simple linear function was added to eliminate the background. This enabled access to the exact values of the various peak positions, widths and maximum peak height intensity. XPS analysis was performed at the SOLEIL Synchrotron (Saclay, France) on the ANTARES beam line. The ring operating conditions were $2.5 \mathrm{GeV}$ electron energy, with injection currents of $500 \mathrm{~mA}$ and "Top-up" mode. Radiation was monochromatized using a plane-grating monochromator (PGM), which is characterized by a slitless entrance and the use of two varied linear spacing (VLS) gratings with variable groove depth (VGD) along the grating lines. The diameter of the $X$-ray spot impinging the surface is $140 \mu \mathrm{m}$ and the $X$-ray energy was fixed at $700 \mathrm{eV}$ for analysis of the graphene films. The photoemission spectra were taken with incident photon energies of 700 and $350 \mathrm{eV}$, with $190 \mathrm{meV}$ and $140 \mathrm{meV}$ energy resolution, respectively.

\subsection{Electrochemical Measurements}

Electrochemical measurements were carried out in a conventional one compartment three electrode cell with an internal volume of $5 \mathrm{~mL}$. This electrochemical cell was designed to maintain a fixed distance between the electrodes. It was manufactured with two inlets, one for positioning the reference electrode and the other for injecting $\mathrm{H}_{2} \mathrm{O}_{2}$. This feature prevented further manipulation or movements of the electrodes (fixing the geometry of the cell and also ensuring the reproducibility of measurements). For this work, a saturated calomel electrode from Hach Lange (Marne-la-Vallée, France) was used as the reference electrode, a planar platinum electrode $\left(0.59 \mathrm{~cm}^{2}\right)$ was used as the counter electrode and the nitrogen doped and undoped graphene samples were the working electrodes. The active surface of the working electrode, determined by a polyethylene terephthalate (PTFE) O-ring seal, was $0.07 \mathrm{~cm}^{2}$. This three-electrode system was connected to a Bio-Logic potentiostat VMP2 (Bio-Logic Science Instruments, Seyssinet-Pariset, France). Results were recorded using EC-Lab software (v11.27) from Bio-Logic Science Instruments. In order to characterize the electron transfer rate 
for the different nitrogen doped and undoped graphene samples, cyclic voltammetry was performed in

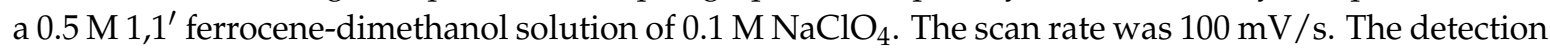
of $\mathrm{H}_{2} \mathrm{O}_{2}$ in a non-deaerated $0.1 \mathrm{M}$ phosphate buffer saline (PBS) solution ( $\mathrm{pH} 7.4$ ) was detected through linear sweep voltammetry in the anodic range from 0 to $1000 \mathrm{mV}$ with a scan rate of $100 \mathrm{mV} / \mathrm{s}$.

\section{Results}

Cyclic voltammetry measurements obtained with ferrocene methanol on pure graphene and NG films are presented in Figure 2, and the main results of the electrochemical measurements are listed in Table 2. The capacitive current appears to be higher with pure graphene film, due to the formation of more edge structures [15].

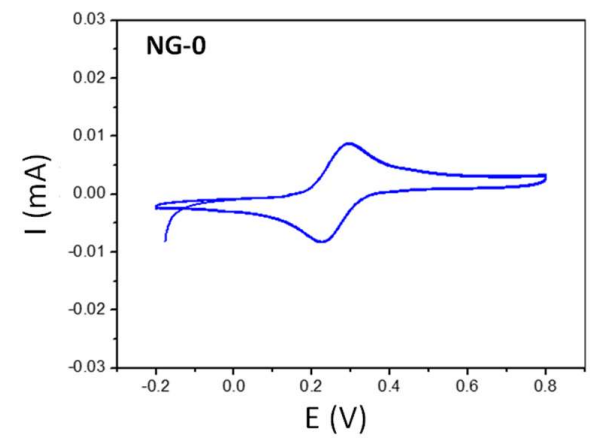

(a)

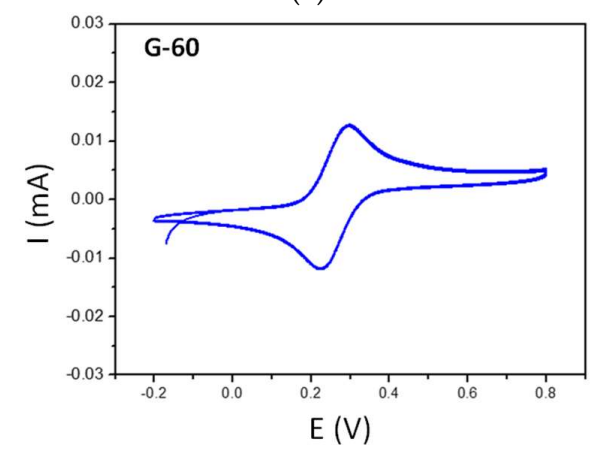

(c)

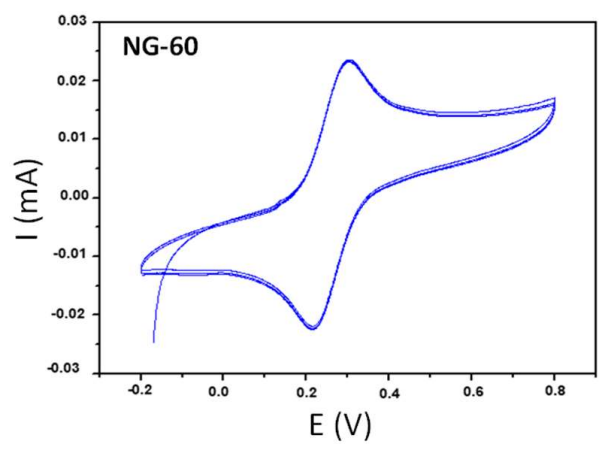

(b)

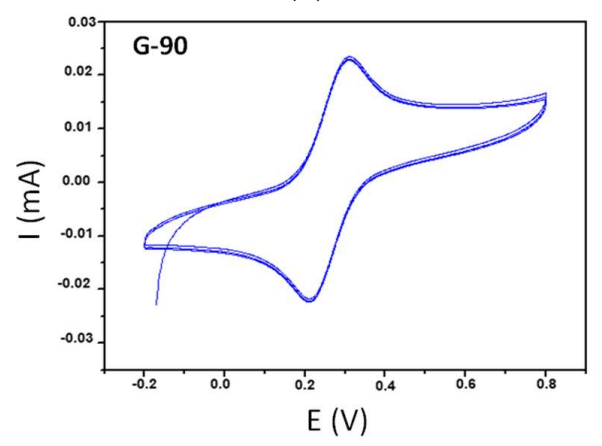

(d)

Figure 2. Cyclic voltammetry on (a) NG-0; (b) NG-60; (c) G-60 and (d) G-90 films, in a $0.5 \mathrm{M}$ $1,1^{\prime}$ ferrocene-dimethanol solution of $0.1 \mathrm{M} \mathrm{NaClO}_{4}$. The scan rate was $100 \mathrm{mV} / \mathrm{s}$.

Table 2. Results of electrochemical measurements on NG and pure graphene films.

\begin{tabular}{cccc}
\hline $\begin{array}{c}\text { Graphene } \\
\text { Films }\end{array}$ & $\begin{array}{c}\text { Anodic Peak } \\
\text { Intensity }\end{array}$ & $\begin{array}{c}\boldsymbol{\Delta E} \text { between Anodic and } \\
\text { Cathodic Peaks }\end{array}$ & $\begin{array}{c}\text { Intensity for } \mathbf{5 0 0} \mathbf{~ m M} \\
\mathbf{H}_{\mathbf{2}} \mathbf{O}_{\mathbf{2}}\end{array}$ \\
\hline NG-0 & $4.0 \mu \mathrm{A}$ & $60 \mathrm{mV}$ & $1200 \mu \mathrm{A}$ \\
\hline NG-60 & $10 \mu \mathrm{A}$ & $78 \mathrm{mV}$ & $700 \mu \mathrm{A}$ \\
\hline G-60 & $5.7 \mu \mathrm{A}$ & $65 \mathrm{mV}$ & $5 \mu \mathrm{A}$ \\
\hline G-90 & $8.7 \mu \mathrm{A}$ & $82 \mathrm{mV}$ & $4 \mu \mathrm{A}$ \\
\hline
\end{tabular}

The length of the annealing time following graphene growth had no significant effect on the intensity of the anodic peak of ferrocene methanol. The value of $\Delta E$ between anodic and cathodic peaks of ferrocene methanol increased with an increase in annealing time for both graphene and NG films. For the NG-0 film, in the absence of annealing following growth, the value of $\Delta E$ was close to the theoretical value of $59 \mathrm{mV}$, showing the high reversibility of the redox probe.

The oxidation of hydrogen peroxide began at a potential value of $600 \mathrm{mV}$ for both types of films, as shown in Figure 3. The values of the oxidation intensities, reported in Table 2 for $500 \mathrm{mM}$ of 
hydrogen peroxide, were measured at a potential value of $1 \mathrm{~V}$. Our results show that the NG-0 film has excellent electrocatalytic properties without additional annealing after graphene growth, leading to the high reversibility of the ferrocene methanol redox probe and high sensitivity for hydrogen peroxide detection, with a detection limit of $1 \mathrm{mM}$ and an oxidation intensity 240 times higher for $500 \mathrm{mM}$ of $\mathrm{H}_{2} \mathrm{O}_{2}$ than undoped G-60 film.

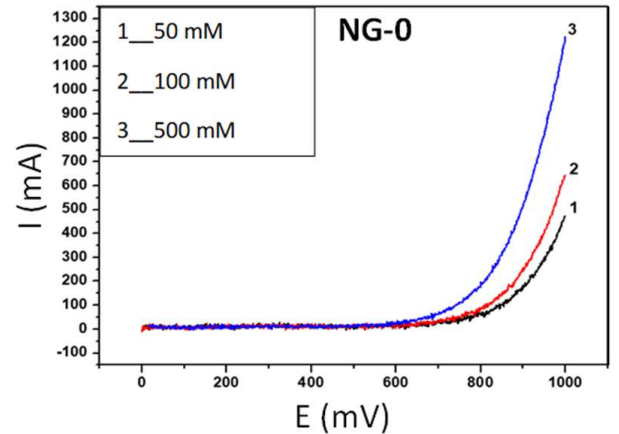

(a)

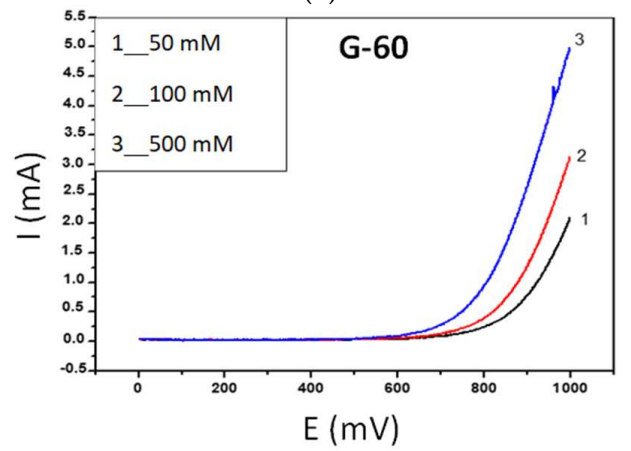

(c)

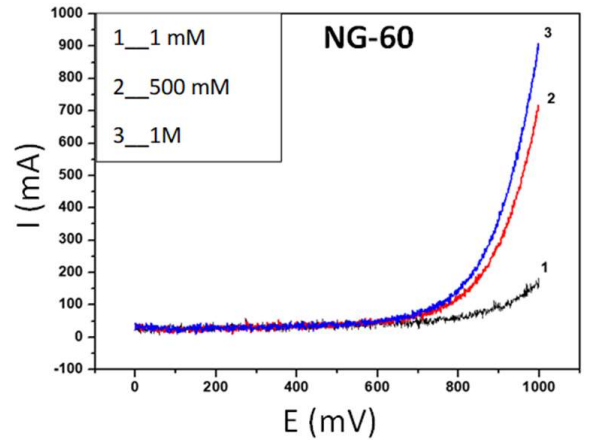

(b)

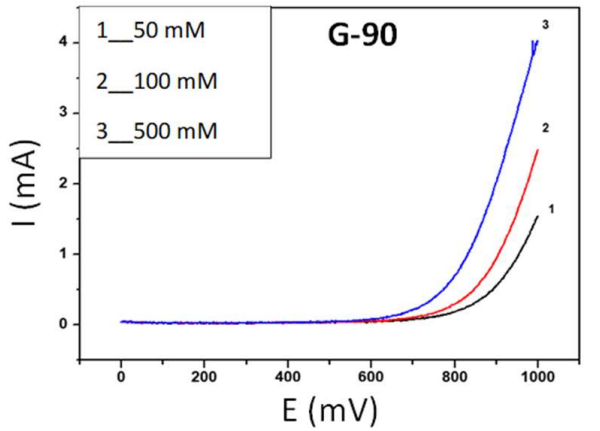

(d)

Figure 3. Linear sweep voltammetry of the (a) NG-0; (b) NG-60; (c) G-60 and (d) G-90 films, in the presence of different concentrations of $\mathrm{H}_{2} \mathrm{O}_{2}$ in $0.1 \mathrm{M}$ PBS solution ( $\mathrm{pH}$ 7.4).

The direct observation of the graphene-covered electrode by FEG-SEM (Figure 4) highlights a textured surface, with grain sizes in the range of $100 \mathrm{~nm}$ whatever the nature of the graphene film. Such a surface architecture is typical of graphene films synthetized on Ni films elaborated by thermal evaporation with subsequent $\mathrm{Ni}$ grain growth during the annealing process used to form the graphene films [9]. We do not observe any significant differences of morphology, with the FEG-SEM resolution at hand, between the four different graphene layers. Probably, the thermal heating during the PLD process is the crucial step inducing such a morphology, and the additional thermal annealing carried out on NG-60, G-60 and G-90 does not affect the surface morphology. Certainly, the nature and composition of the films, as deduced from XPS and Raman investigations, with such a significant difference between undoped and N-doped graphene films versus thermal annealing, is worth underlining. XPS was carried out on the NG-0 film obtained without post-annealing, given the significant electroanalytical result related to hydrogen peroxide oxidation. In Figure 5A, the XPS survey spectrum of the NG-0 film shows carbon located near $284 \mathrm{eV}$, nitrogen located near $400 \mathrm{eV}$, and some traces of oxygen near $533 \mathrm{eV}$.

The $\mathrm{N} / \mathrm{C}$ intensity ratio deduced from the spectra was 0.01786 , which is consistent with a nitrogen doping of 1.75 at \%. Figure 5B shows deconvolution of the $\mathrm{C} 1 \mathrm{~s}$ into three components. The most intense component was centered at $284.4 \mathrm{eV}$ and was attributed to $s p^{2}$ hybridized $\mathrm{C}$ atoms in graphene. The two other ones were located at 284.9 and $285.8 \mathrm{eV}$, respectively. The component at $284.9 \mathrm{eV}$ was attributed to disordered carbon $\left(C_{\mathrm{B}}\right)$ and may be considered as an intermediate state between $s p^{2}$ and $s p^{3}$ hybridizations that can be found in nano-diamond and amorphous carbon films, in agreement with References [16-18]. 
The component at $285.8 \mathrm{eV}$ was attributed to $\mathrm{C}-\mathrm{N}$ or $\mathrm{C}-\mathrm{O}$ bonds $[19,20]$. However, it is known that the peak of $\mathrm{C}-\mathrm{O}$ is overlaid with $\mathrm{C}-\mathrm{N}$; therefore, it may be difficult to discriminate between the $\mathrm{C}-\mathrm{N}$ and $\mathrm{C}-\mathrm{O}$ oxygen group $[4,9,12]$.

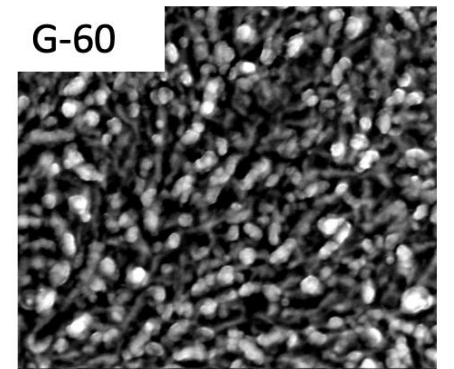

(a)

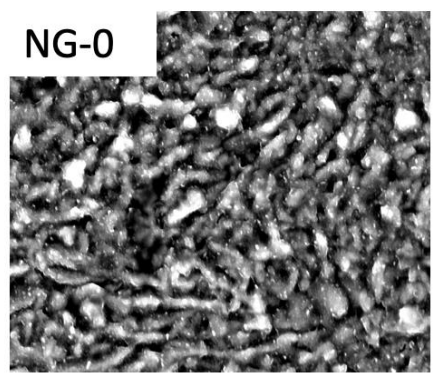

(c)

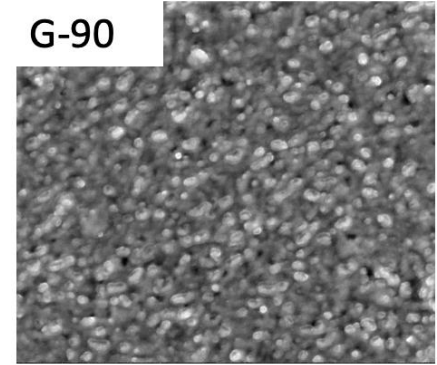

(b)

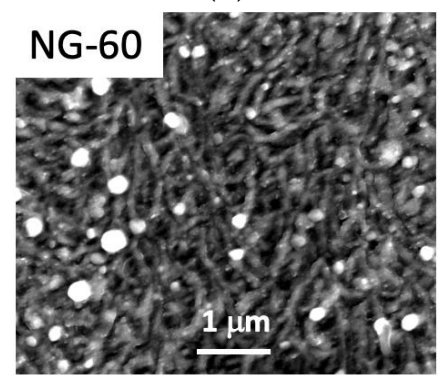

(d)

Figure 4. FEG-SEM images of (a) pure graphene with $60 \mathrm{mn}$ post-deposition annealing; (b) pure graphene with $90 \mathrm{mn}$ post-deposition annealing; (c) N-doped graphene with no post-deposition annealing; (d) $\mathrm{N}$-doped graphene with $60 \mathrm{mn}$ post-deposition annealing. The sub-micrometer texture was attributed to the texturing of the Ni catalyst film caused by thermal annealing. The four images are depicted with the same magnification $1 \mu \mathrm{m}$ as noted on the image related to NG-60.
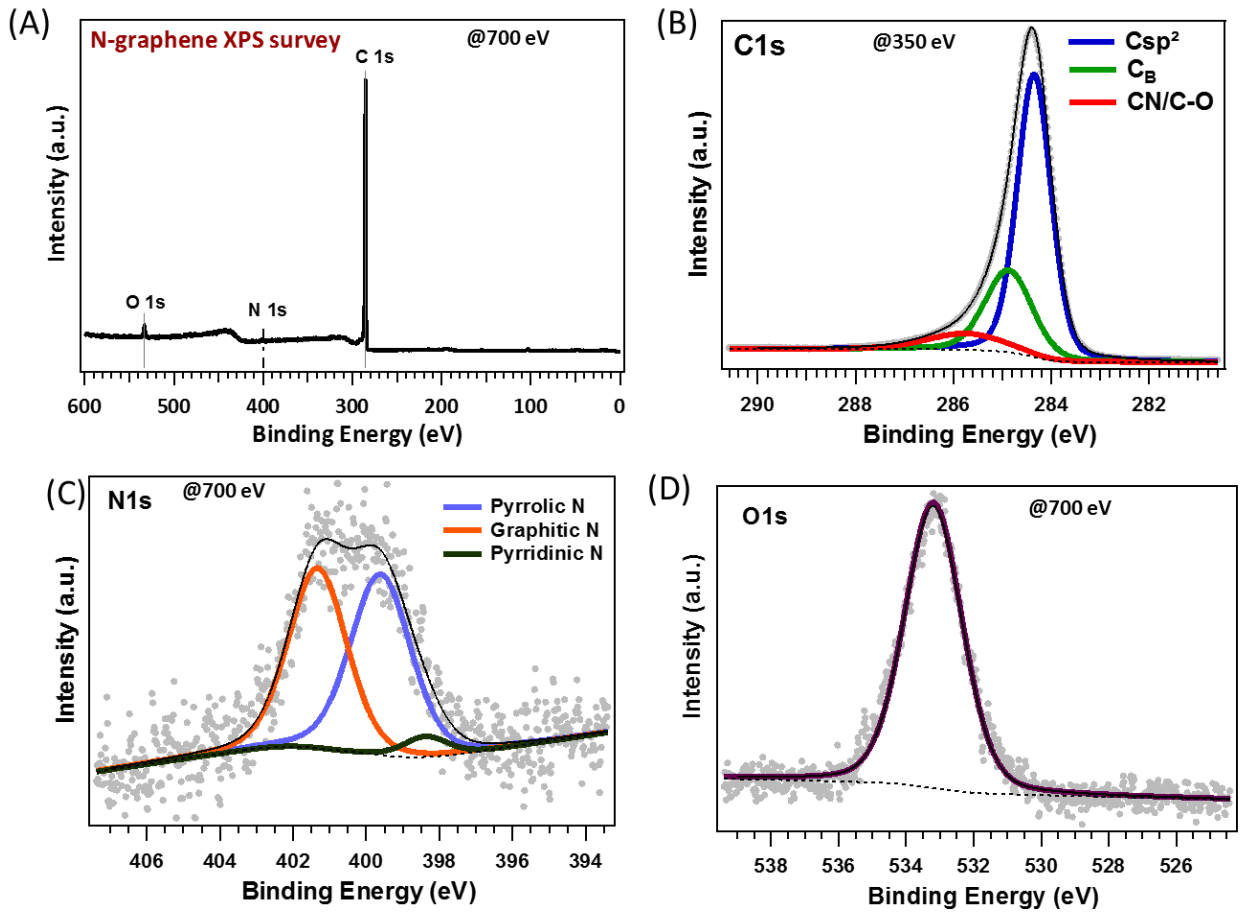

Figure 5. XPS spectra of the N-doped NG-0 graphene film; (A) XPS $700 \mathrm{eV}$ overview spectrum; (B) XPS $350 \mathrm{eV} \mathrm{C1s} \mathrm{core} \mathrm{level} \mathrm{spectrum;} \mathrm{(C)} \mathrm{XPS} 700$ eV N1s core level spectrum; and (D) XPS 700 eV O1s core level spectrum. 
Raman results related to the undoped and doped graphene films are shown in Figure 6. All the samples had the bands traditionally found in Raman spectrometry graphene materials; these results are in agreement with those reported in References [21,22]. For graphene films, the D, G and $2 \mathrm{D}$ bands are the most significant for the characterization of the thin film structure. The $\mathrm{G}$ band is associated with covalent $\mathrm{C}-\mathrm{C}$ bonding vibrations in the graphite matrix and is present in every carbon material containing $s p^{2}$ bonding. The $\mathrm{D}$ band is associated with the pulsation of aromatic circles ("breathing mode") and appears only in the presence of defects and dislocations in the graphitic matrix. The intensity ratio between the $D$ band and $G$ band $(D / G)$ is thus an indication of disorder in the carbon structure. The 2D band is associated with a double resonance Raman scattering process between two aromatic circles. It appears in both graphene and graphite, and the intensity ratio of the $2 \mathrm{D}$ band versus the $\mathrm{G}$ band $(2 \mathrm{D} / \mathrm{G})$ is a good indicator of the graphene-like quality of a thin film, a ratio higher than 1 being indicative of monolayer graphene. In non-defective graphene, the study of the 2D peak position and width is also a good way to count the number of layers and to identify their stacking configuration $[22,23]$. Additional D $+\mathrm{D}^{\prime \prime}, \mathrm{D}+\mathrm{D}^{\prime}$ and 2D' bands are also observed in Figure 6. The D $+\mathrm{D}^{\prime \prime}$ and 2D' peaks are, as the $\mathrm{G}$ and 2D peaks, usual features in most graphene samples [24]. They emerge, like the 2D peak, as a combination of two phonon mode individually associated with defects $\left(\mathrm{D}^{\prime}\right.$ and $\left.\mathrm{D}^{\prime \prime}\right)$ allowing so-called breathing of aromatic rings in carbon materials. The combination of those resonances can appear without defects as the two phonons can verify momentum conservation provided they have opposite wavevectors. In the case of the $\mathrm{D}+\mathrm{D}^{\prime}$ band, also sometimes labelled as $D+G$, the comprehension of excitation mechanisms remains rather unclear, but whether it is a combination of $\mathrm{D}$ and $\mathrm{G}$ phonons or $\mathrm{D}$ and $\mathrm{D}^{\prime}$ does not change the fact that respectively one or both of the phonons need a defect to arise. Thus, the $\mathrm{D}+\mathrm{D}^{\prime}$ band mostly appears in defective graphene-like material [25], which explains its presence in our materials.

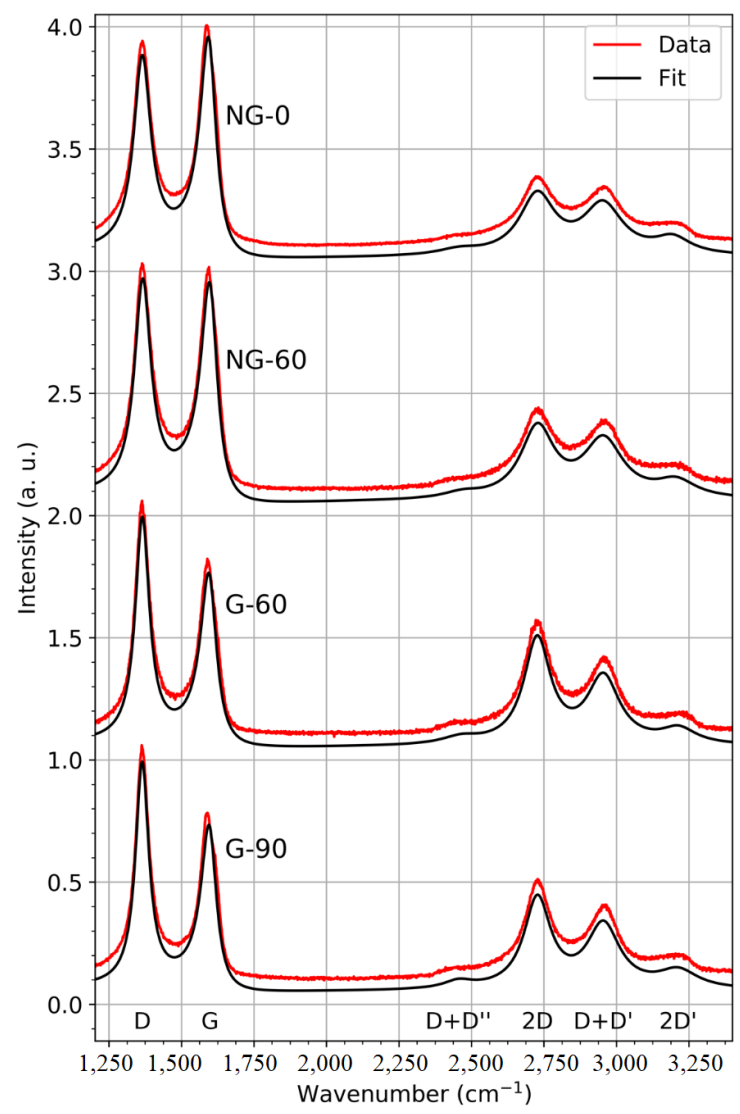

Figure 6. Typical Raman spectra of undoped and N-doped graphene films. The temperature during PLD graphene synthesis was $780{ }^{\circ} \mathrm{C}$ in all cases. Post-annealing times (min) are indicated in parentheses. 
All the Raman spectra shown in Figure 6 present a higher D band compared to the G band, implying a very defective nature of the thin films. The 2D peak maximum was always lower than the $G$ peak maximum, which may be associated with the multilayer nature of the graphene. A reduction in the 2D band in N-doped samples should also be noted; this is expected when nitrogen is introduced in the graphene matrix [13], although one would also expect an increase in the D/G ratio [26], which was not the case here. Typical maps of peak ratios, like the one in Figure 7 related to the multilayer pure graphene sample obtained with $90 \mathrm{mn}$ post-annealing, enable evaluation of the uniformity of the synthesized thin films. In the case of pure graphene, a relative lack of uniformity appears in both the $2 \mathrm{D} / \mathrm{G}$ and $\mathrm{D} / \mathrm{G}$ ratios, with respective variations from 0.5 to 0.9 and from 1.0 to 1.3. The lack of homogeneity at the micrometric scale is consistent with the defective nature of the film. A slight correlation between areas with low $\mathrm{D} / \mathrm{G}$ ratio and low $2 \mathrm{D} / \mathrm{G}$ ratio can be observed, consistent with a slightly higher number of defects in areas where there are fewer graphene layers.

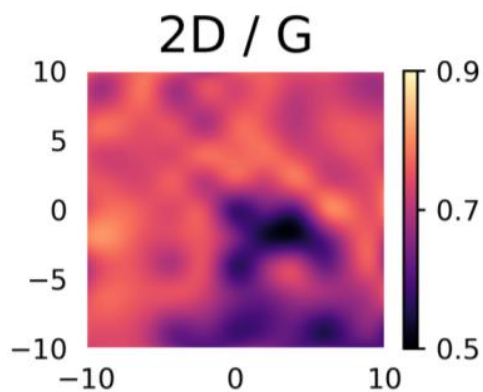

(a)

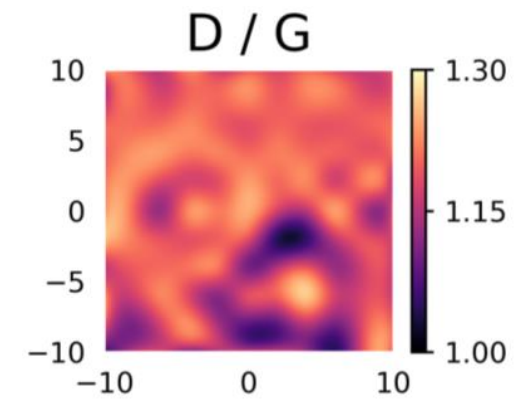

(b)

Figure 7. Maps of the Raman (a) 2D/G and (b) D/G intensity ratios recorded at the $442 \mathrm{~nm}$ excitation wavelength on a $20 \times 20 \mu \mathrm{m}^{2}$ area of the pure graphene film annealed at $780^{\circ} \mathrm{C}$ for $90 \mathrm{~min}(\mathrm{G}-90)$. $X-Y$ scales in $\mu \mathrm{m}$.

Figure 8 shows the impact of incorporating nitrogen in the sample synthesized at $780{ }^{\circ} \mathrm{C}$ with no post-annealing. The intensity ratio of the $2 \mathrm{D}$ and $\mathrm{G}$ peaks exhibit considerably less variation than in Figure 7, whereas the D/G intensity ratios still show high variability (note that in Figures 7 and 8 the scales of the color bars are not the same) but are generally lower. This may mean that incorporating nitrogen helps to stabilize the multilayer graphene on the substrate, giving it a more organized structure.

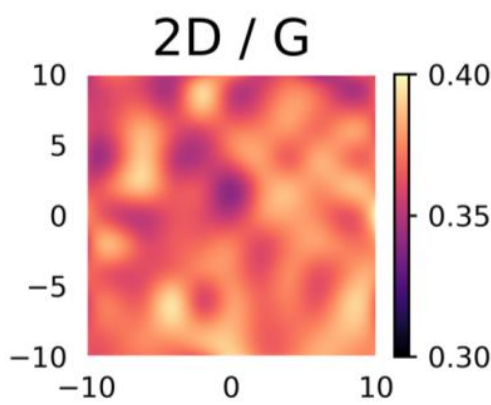

(a)

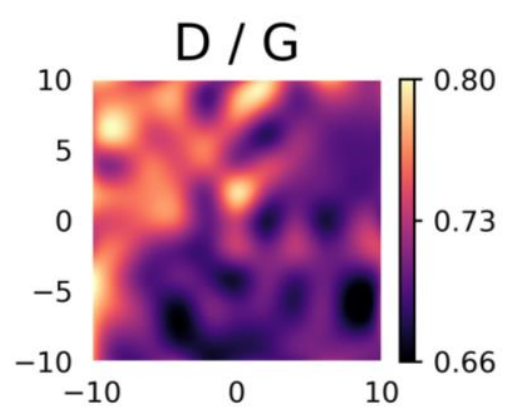

(b)

Figure 8. Maps of the Raman (a) $2 D / G$ and (b) D/G intensity ratios recorded at an excitation wavelength of $442 \mathrm{~nm}$ on a $20 \times 20 \mu \mathrm{m}^{2}$ area of the $\mathrm{N}$-doped graphene film with no post-deposition annealing (NG-0). $X-Y$ scales in $\mu \mathrm{m}$.

The Raman findings are summarized in Table 3 where the average fit parameters obtained for scanned areas relate to the four samples. As mentioned above, we focused on the $D, G$ and 2D peak parameters. The $2 D / G$ and $D / G$ intensity ratios further confirm the information provided by Figure 6 . 
Pure graphene samples exhibited higher ratios of both the 2D/G and D/G bands than the N-doped graphene samples.

Table 3. Average Raman fit parameters and parameter ratios for four undoped and doped multilayer graphene samples with different post-annealing durations. The standard deviation for each parameter is in parentheses.

\begin{tabular}{|c|c|c|c|c|c|c|c|c|}
\hline \multirow{2}{*}{ Samples } & \multicolumn{2}{|c|}{$\begin{array}{c}\text { Intensity Ratio } \\
\text { (Standard Deviation) }\end{array}$} & \multicolumn{3}{|c|}{$\begin{array}{c}\text { Peak Position }\left(\mathrm{cm}^{-1}\right) \\
\left.\text { (Standard Deviation }\left(\mathrm{cm}^{-1}\right)\right)\end{array}$} & \multicolumn{3}{|c|}{$\begin{array}{l}\text { Peak Full Width Half Maximum }\left(\mathrm{cm}^{-1} \text { ) }\right. \\
\text { (Standard Deviation }\left(\mathrm{cm}^{-1}\right) \text { ) }\end{array}$} \\
\hline & $2 D / G$ & $D / G$ & D & G & $2 \mathrm{D}$ & D & G & $2 \mathrm{D}$ \\
\hline NG-0 & $\begin{array}{c}0.369 \\
(0.011)\end{array}$ & $\begin{array}{c}0.722 \\
(0.032)\end{array}$ & $\begin{array}{c}1365.6 \\
(0.7)\end{array}$ & $\begin{array}{c}1589.8 \\
(1.7)\end{array}$ & $\begin{array}{l}2721.7 \\
(1.9)\end{array}$ & $78.2(2.0)$ & $73.9(0.8)$ & $139(3.2)$ \\
\hline NG-60 & $\begin{array}{c}0.386 \\
(0.011)\end{array}$ & $\begin{array}{c}0.903 \\
(0.026)\end{array}$ & $\begin{array}{c}1366.8 \\
(0.6)\end{array}$ & $\begin{array}{l}1595.0 \\
(1.00)\end{array}$ & $\begin{array}{c}2724.4 \\
(1.9)\end{array}$ & $69.5(2.1)$ & 71.0 (1.4) & $129.0(5.0)$ \\
\hline G-60 & $\begin{array}{c}0.659 \\
(0.036)\end{array}$ & $\begin{array}{l}1.242 \\
(0.029)\end{array}$ & $\begin{array}{c}1365.6 \\
(0.8)\end{array}$ & $\begin{array}{c}1594.5 \\
(1.0)\end{array}$ & $\begin{array}{c}2727.0 \\
(1.7)\end{array}$ & $59.5(1.4)$ & $68.1(2.1)$ & $111.1(2.6)$ \\
\hline G-90 & $\begin{array}{c}0.712 \\
(0.060)\end{array}$ & $\begin{array}{c}1.183 \\
(0.042)\end{array}$ & $\begin{array}{c}1365.9 \\
(0.8)\end{array}$ & $\begin{array}{c}1591.9 \\
(1.7)\end{array}$ & $\begin{array}{c}2726.2 \\
(2.0)\end{array}$ & $60.4(5.2)$ & 66.8 (3.1) & $108.4(4.6)$ \\
\hline
\end{tabular}

It should be noted that, in the course of this study, further post-annealing durations were tested in addition to those presented here. It was impossible to obtain any kind of pure graphene material without at least $30 \mathrm{~min}$ of post-deposition annealing. However, it was possible to synthesize an $\mathrm{N}$-doped graphene film without post-annealing, i.e., the substrate was left to cool naturally immediately after the a-C:N pulsed-laser deposition. We would like to underline that this possibility implies an effect of the nitrogen environment on the catalysis of graphene growth by $\mathrm{Ni}$, which opens the way for a more rapid fabrication of $\mathrm{N}$-doped graphene. This also implies that, despite the high temperature used for graphene synthesis using annealing on a nickel catalyst, the as-deposited carbon structure may have a strong influence on the catalytic process. Additionally, it appears that lengthening the post-annealing period is an advantage with pure few-layer graphene, as the peak $\mathrm{D} / \mathrm{G}$ ratio decreased and the 2D/G ratio increased when post-annealing time was increased from 60 to $90 \mathrm{~min}$. This is in contrast to the fact that for $\mathrm{N}$-doped graphene films, post-annealing only appeared to increase the $\mathrm{D} / \mathrm{G}$ ratio, pointing to a higher number of defects.

All the observed peaks appear to be more intense than those of monocrystalline non-defective graphite or graphene. The full width at half maximum (FWHM) of the G peak is generally around $15 \mathrm{~cm}^{-1}$ [22] while here it was $70 \mathrm{~cm}^{-1}$. The width of this peak may be associated with the distortion of the $\mathrm{C}-\mathrm{C} s p^{2}$ bonding angle. This is to be expected due to the nanotexturing of our samples, as observed by FEG-SEM shown in Figure 4. The position of the peak was also always upshifted here compared to graphite or monolayers graphene, i.e., between 1590 and $1595 \mathrm{~cm}^{-1}$ compared to $1582 \mathrm{~cm}^{-1}$ [22].

These characteristics, combined with the high $D$ versus $G$ peak intensities ratio, are clear indicators of highly nano-crystallized graphene-like layers. The broadening of all peaks due to the nanotexturing of the substrate during annealing makes it impossible to draw clear conclusions concerning the precise number of graphene layers by studying the 2D band Full Width Half Maximum (FWHM).

\section{Discussion}

The objective of this section is to discuss the significant improvement of electroanalytical oxidation of $\mathrm{H}_{2} \mathrm{O}_{2}$ by the $\mathrm{N}$-doped graphene films compared to undoped ones in more detail. What is the main effect among the defective nature of the $\mathrm{N}$-doped graphene films, the dopant concentration or the nature/proportion of the nitrogen chemical functions in the graphene network?

According to the previous section, the morphologies of all films (doped and undoped) appear to be textured, probably due to the texturing of the nickel catalyst surface caused by thermal annealing. We previously showed that the formation of nickel silicide contributed to texturing when graphene was grown on a silicon substrate covered by a Ni thin film [27]. 
Likewise, all films have a defective structure, as shown by Raman investigations, and nitrogen doping at a concentration as low as 1.6 at \% does not significantly influence the defective structure of graphene, which is probably inherent to the synthesis process, as already observed by Schiros et al., who compared CVD synthesis of graphene and N-doped graphene films [28]. Moreover, when extended beyond the $\mathrm{N}$-doped graphene synthesis, heat treatments do not cause significant changes to the nanoarchitecture of graphene film in terms of texture and number of graphene layers. Based on the comparison of the $2 \mathrm{D} / \mathrm{G}$ and $\mathrm{D} / \mathrm{G}$ ratio maps, the textured films are heterogeneous and the concentration of defects was slightly higher in areas where there are fewer layers of graphene.

However, a huge difference in electroanalytical oxidation of $\mathrm{H}_{2} \mathrm{O}_{2}$ was observed between undoped and $\mathrm{N}$-doped graphene films, and the difference was more pronounced when the heat treatment was limited during the PLD film growth in the presence of nitrogen gas. The in situ nitrogen doping process during PLD graphene growth described in the previous section, led to the formation of a few-layer graphene film containing 1.75 at \% of nitrogen, with a similar proportion of pyrrolic-N and graphitic-N, and a negligible amount of pyridinic-N. According to the literature, in particular, in Wang et al. [4] and in Shao et al. [5], the presence of incorporated nitrogen induces a change in the Fermi level, which is responsible for the doping effect and opens the band gap of the graphene structure, thus enhancing electrochemical reactivity. The high level of electronic state density and the efficient quantity of free electrons in $\mathrm{N}$-doped graphene facilitates $\mathrm{H}_{2} \mathrm{O}_{2}$ oxidation. In particular, carbon atoms adjacent to nitrogen dopants may have a substantially positive charge density to counterbalance the higher electronic affinity of $\mathrm{N}$ atoms, consistent with the increased adsorption of $\mathrm{H}_{2} \mathrm{O}_{2}$ involved in the oxidation reaction. Such a mechanism has also been shown by density functional theory (DFT) simulating the physisorption process of $\mathrm{H}_{2} \mathrm{O}_{2}$ onto graphene-based surfaces [29]. Additionally, the structural defects resulting from $\mathrm{N}$ doping increased the amount of unsaturated carbon atoms located at graphene edge sites, which appeared to be very active in reacting with oxygen containing groups. During $\mathrm{H}_{2} \mathrm{O}_{2}$ electrocatalytic oxido-reduction, the $\mathrm{O}-\mathrm{O}$ bond in $\mathrm{H}_{2} \mathrm{O}_{2}$ was more easily broken at the surface of $\mathrm{N}$-doped graphene because $\mathrm{N}$ doping induced the charge delocalization of graphene. With our NG-0 film, in the absence of annealing following growth, the oxidation of $\mathrm{H}_{2} \mathrm{O}_{2}$ began at a potential value of $600 \mathrm{mV}$. This value is rather high compared to that reported by Wang et al. (200 mV), who observed a four times higher $\mathrm{H}_{2} \mathrm{O}_{2}$ oxidation signal with the NG films compared to the undoped ones [4]. Our results show that the NG-0 film presents excellent electrocatalytic properties leading to the high reversibility of the ferrocene methanol redox probe and high sensitivity for hydrogen peroxide detection, with a detection limit of $1 \mathrm{mM}$. A 240 times higher $\mathrm{H}_{2} \mathrm{O}_{2}$ oxidation signal was observed for the NG-0 film compared to the average value obtained with the undoped graphene films.

Such high electroanalytical reactivity is generally attributed both to chemical functionalization (both pyrrolic, pyridinic and graphitic nitrogen-carbon forms are generally reported in the literature) and to structural defects caused by nitrogen atoms. However, based on our experiments, the nature and proportions of the various $\mathrm{N}-\mathrm{C}$ chemical functions certainly play a more significant role in the electroanalytical oxidation of $\mathrm{H}_{2} \mathrm{O}_{2}$ than the number of defects, which is similar with or without $\mathrm{N}$ doping. Such an influence was already highlighted by $\mathrm{Xu}$ et al. [3]. According to these authors, the relationship between the nature of $\mathrm{N}$ functions and the properties of $\mathrm{N}$-doped graphene needs to be clarified, so that more desirable properties for specific applications can be selected. Based on experimental and theoretical (DFT calculations) considerations $[28,30]$, the nature and level of doping in N-doped graphene depends on the proportion of the three main functional groups: graphitic- $\mathrm{N}$ is responsible for an $\mathrm{n}$-doping effect and pyridinic-N and pyrrolic-N are responsible for a p-doping effect. The balance between the three chemical functions may strongly affect the electroanalytical performance of the $\mathrm{N}$-doped graphene. More precisely, nitrogen in the graphitic-N configuration has 4 of the 5 electrons filling in the $\sigma$ - and $\pi$-orbitals, leaving one extra electron. About $50 \%$ of the additional charge is localized on the $\mathrm{N}$ dopant coupled with its nearest carbon neighbors, whereas the remaining $50 \%$ is distributed in the local network of carbon $\pi$-states, thus inducing n-doping and preserving high electron mobility. Pyridinic-N and pyrrolic-N dopants have the opposite electronic effect, as they 
withdraw charge from their carbon neighbors. In the case of pyridinic- $\mathrm{N}$, two electrons fill $\sigma$ bonds with carbon neighbors, and two electrons form a lone pair in the graphene plane. The remaining electron occupies the nitrogen $\pi$-state. As a consequence, pyridinic- $\mathrm{N}$ is the equivalent of a nominal carbon in graphene, but an $\pi$ electron is missing due to the vacant site, hence $\mathrm{p}$-doping the graphene. Our NG-0 film contained $49 \%$ of graphitic-N and $47 \%$ of pyrrolic-N, whereas pyridinic-N contents were as low as $4 \%$. With a 1.35 at $\% \mathrm{~N}$ content close to our doping concentration (1.75 at \%), Wang et al. [4] obtained a nitrogen-doped graphene film with significantly higher proportions of pyrrolic- $\mathrm{N}$ and pyridinic-N and a lower proportion of graphitic-N than we obtained. We conclude that our nitrogen doping process induced a rather higher proportion of mixed graphitic- $\mathrm{N}$ and pyrrolic- $\mathrm{N}$ than other $\mathrm{N}$-doped graphene films reported in the literature, and this may be responsible for the very high electroanalytical $\mathrm{H}_{2} \mathrm{O}_{2}$ oxidation performance. However, our results do not follow the reactivity scale simulated by DFT by Wu et al. [29] who concluded that $\mathrm{H}_{2} \mathrm{O}_{2}$ oxidation reactivity occurred in the following order: pyridinic-N > Pyrrolic-N > Graphitic-N > Pristine graphene. However, it is difficult to compare DFT calculations performed with only one nitrogen-based function, even if true, with an experimental system comprised of a mixture of nitrogen-based functions embedded in a textured few-layer graphene material. Further studies are thus recommended to optimize $\mathrm{N}$-doped graphene films with better control of the N-based chemical functions, in particular with distinct proportions of the various N-based functions, in order to confirm their effect as key factors for electrochemical applications of N-doped graphene films.

\section{Conclusion}

Here we report on experimental work on the electroanalytical performance of $\mathrm{N}$-doped graphene silicon-based electrodes, obtained in one step by pulse laser deposition of carbon performed in a vacuum at high temperature, in the presence of a surrounding nitrogen atmosphere. The main conclusions are the following:

- The electrode is covered by a few-layer defective and textured $\mathrm{N}$-doped graphene film, containing 1.75 at $\%$ of nitrogen distributed in both graphitic-N and pyrrolic-N chemical functions at similar proportions.

- With the ferrocene methanol system, the electrode displays excellent reversibility, $60 \mathrm{mV}$, close to the theoretical value of $59 \mathrm{mV}$, and very high sensitivity for hydrogen peroxide oxidation characterized by an intensity 240 times higher than that obtained with undoped graphene synthetized using the same process, and a detection limit of $1 \mathrm{mM}$ of hydrogen peroxide.

- These significant electroanalytical results are correlated with the amount of $\mathrm{N}$ doping and with the proportion of both graphitic-N and pyrrolic-N chemical functions incorporated into the defective and textured few-layer graphene film.

- Additional heat treatment following the deposition process does not significantly modify the nanoarchitecture of the $\mathrm{N}$-doped graphene films and slightly decreases the electroanalytical performance in terms of reversibility and hydrogen peroxide oxidation performance, compared to the $\mathrm{N}$-doped films obtained with no additional heating.

Further works are recommended to achieve better control of the different N-based chemical functions embedded in the graphene network and to quantify their effects on the electroanalytical performances of $\mathrm{N}$-doped graphene electrodes.

Author Contributions: Conceptualization, C.D., N.J.-R., C.C., M.-C.A. and F.G.; Methodology, F.B., A.-S.L. and C.F.; Investigation, Y.B., G.R., B.C.-M., J.A., M.S. and I.R.; Resources, V.B.; Writing-Original Draft Preparation, C.D., F.B., Y.B. and N.J.-R.; Writing-Review \& Editing, C.D.; Visualization, C.D.; Supervision, C.D., F.G. and N.J.-R..; Project Administration, F.B. and C.D.

Funding: This research was funded by the program PEPS “Risques et Environnement 2016" of Université de Lyon-CNRS ("PEPS 3D-GraPS"), and by the LABEX MANUTECH-SISE (ANR-10-LABX-0075) of Université de Lyon, within the program "Investissements d'Avenir" (ANR-11-IDEX-0007) operated by the French National Research Agency (ANR). This research was partly funded by CAMPUS FRANCE, through PHC Maghreb 
\#39382RE. Maryam Shokouhi thanks the ministry of Science, Research and Technology, Islamic Republic of IranDepartment of Scholarships and Overseas Students' Affairs for the grant.

Conflicts of Interest: The authors declare no conflict of interest.

\section{References}

1. Lu, W.; Soukiassian, P.; Boeckl, J. Graphene: Fundamentals and functionalities. MRS Bull. 2012, 37, 1119-1124. [CrossRef]

2. Yadav, R.; Dixit, C.K. Synthesis, characterization and prospective applications of nitrogen-doped graphene: A short review. J. Sci. Adv. Mater. Dev. 2017, 2, 141-149. [CrossRef]

3. Xu, H.; Ma, L.; Jin, Z. Nitrogen-doped graphene: Synthesis, characterizations and energy applications. J. Energy Chem. 2018, 27, 146-160. [CrossRef]

4. Wang, Y.; Shao, Y.; Matson, D.W.; Li, J.; Lin, Y. Nitrogen-doped graphene and its application in electrochemical biosensing. ACS Nano 2010, 4, 1790-1798. [CrossRef] [PubMed]

5. Shao, Y.; Zhang, S.; Engelhard, M.H.; Li, G.; Shao, G.; Wang, Y.; Liu, J.; Aksay, I.A.; Lin, Y. Nitrogen-doped graphene and its electrochemical application. J. Mater. Chem. 2010, 20, 7491-7496. [CrossRef]

6. Li, R.; Liu, L.; Bei, H.; Li, Z. Nitrogen-doped multiple graphene aerogel/gold nanostar as the electrochemical sensing platform for ultrasensitive detection of circulating free DNA in human serum. Biosens. Bioelectron. 2016, 79, 457-466.

7. Saengsookwaow, C.; Rangkupan, R.; Chailapakul, O.; Rodthongkum, N. Nitrogen-doped multiple graphene-polyvinylpyrrolidone/gold nanoparticles modified electrode as a novel hydrazine sensor. Sens. Actuators 2016, 227, 524-532. [CrossRef]

8. Li, X.; Zhao, H.; Shi, L.; Zhu, X.; Lan, M.; Zhang, Q.; Fan, Z.H. Electrochemical sensing of nicotine using screen-printed carbon electrodes modified with nitrogen-doped graphene sheets. J. Electroanal. Chem. 2017, 784, 77-84. [CrossRef]

9. Fortgang, P.; Tite, T.; Barnier, V.; Zehani, N.; Maddi, C.; Lagarde, F.; Loir, A.-S.; Jaffrezic-Renault, N.; Donnet, C.; Garrelie, F.; et al. Robust electrografting on self-organized 3D graphene electrodes. ACS Appl. Mater. Interfaces 2015, 8, 1424-1433. [CrossRef] [PubMed]

10. Bleu, Y.; Bourquard, F.; Tite, T.; Loir, A.-S.; Maddi, C.; Donnet, C.; Garrelie, F. Review of graphene growth from a solid carbon source by pulsed laser deposition (PLD). Front. Chem. 2018, 6, 574. [CrossRef] [PubMed]

11. Kumar, S.R.; Nayak, P.K.; Hedhili, M.N.; Khan, M.A.; Alshareef, H.N. In situ growth of p and n-type graphene thin films and diodes by pulsed laser deposition. Appl. Phys. Lett. 2013, 103, 192109. [CrossRef]

12. Ren, P.; Pu, E.; Liu, D.; Wang, Y.; Xiang, B.; Ren, X. Fabrication of nitrogen-doped graphenes by pulsed laser deposition and improved chemical enhancement for Raman spectroscopy. Mater. Lett. 2017, 204, 65-68. [CrossRef]

13. Maddi, C.; Bourquard, F.; Barnier, V.; Avila, J.; Asensio, M.C.; Tite, T.; Donnet, C.; Garrelie, F. Nano-architecture of nitrogen-doped graphene films synthesized from a solid CN source. Sci. Rep. 2018, 8, 3247. [CrossRef] [PubMed]

14. Szatrowski, T.P.; Nathan, C.F. Production of large amounts of hydrogen peroxide by human cells. Cancer Res. 1991, 51, 794-798. [PubMed]

15. Zribi, B.; Castro-Arias, J.M.; Decanini, D.; Gogneau, N.; Dragoe, D.; Cattoni, A.; Ouerghi, A.; Korri-Youssoufi, H.; Haghiri-Gosnet, A.M. Large area graphene nanomesh: An artificial platform for edge-electrochemical biosensing at the sub-attomolar level. Nanoscale 2016, 8, 15479-15485. [CrossRef] [PubMed]

16. Blume, R.; Rosenthal, D.; Tessonnier, J.-P.; Li, H.; Knop-Gericke, A.; Schlög, R. Characterizing graphitic carbon with X-ray photoelectron spectroscopy: A step-by-step approach. ChemCatChem 2015, 7, 2871-2881. [CrossRef]

17. Weathertrup, R.S.; Bayer, B.C.; Blume, R.; Ducati, C.; Baehtz, C.; Schlögl, R.; Hofmann, S. In situ characterization of alloy catalysts for low-temperature graphene growth. Nano Lett. 2011, 11, 4154-4160. [CrossRef] [PubMed]

18. Ma, K.; Tang, J.; Zou, Y.; Ye, Q.; Zhang, W.; Lee, S. Photoemission spectroscopic study of nitrogen-incorporated nanocrystalline diamond films. Appl. Phys. Lett. 2007, 90, 92105. [CrossRef] 
19. Malitesta, C.; Losito, I.; Sabbatini, L.; Zambonin, P.G. New Findings on Polypyrrole Chemical Structure by XPS Coupled to Chemical Derivatization Labelling. J. Electron Spectrosc. Relat. Phenom. 1995, 76, 629-634. [CrossRef]

20. Ganguly, A.; Sharma, S.; Papakonstantinou, P.; Hamilton, J. Probing the thermal deoxygenation of graphene oxide using high-resolution in situ X-ray-based spectroscopies. J. Phys. Chem. C 2011, 115, 17009-17019. [CrossRef]

21. Ferrari, A.C.; Meyer, J.C.; Scardaci, V.; Casiraghi, C.; Lazzeri, M.; Mauri, F.; Piscanec, S.; Jiang, D.; Novoselov, K.S.; Roth, S.; et al. Raman spectrum of graphene and graphene layers. Phys. Rev. Lett. 2006, 97, 187401. [CrossRef] [PubMed]

22. Malard, L.M.; Pimenta, M.A.; Dresselhaus, G.; Dresselhaus, M.S. Raman spectroscopy of graphene. Phys. Rep. 2009, 473, 51-87. [CrossRef]

23. Park, J.S.; Reina, A.; Saito, R.; Kong, J.; Dresselhaus, G.; Dresselhaus, M.S. G' band Raman spectra of single, double and triple layer graphene. Carbon 2009, 47, 1303-1310. [CrossRef]

24. Ferrari, A.C.; Basko, D.M. Raman spectroscopy as a versatile tool for studying the properties of graphene. Nat. Nanotechnol. 2013, 8, 235-246. [CrossRef] [PubMed]

25. Iqbal, M.W.; Singh, A.K.; Iqbal, M.Z.; Eom, J. Raman fingerprint of doping due to metal adsorbates on graphene. J. Phys. Condens. Matter 2012, 24, 335301. [CrossRef] [PubMed]

26. Zhang, C.; Fu, L.; Liu, N.; Liu, M.; Wang, Y.; Liu, Z. Synthesis of nitrogen-doped graphene using embedded carbon and nitrogen sources. Adv. Mater. 2011, 23, 1020-1024. [CrossRef] [PubMed]

27. Tite, T.; Barnier, V.; Donnet, C.; Loir, A.-S.; Reynaud, S.; Michalon, J.-Y.; Vocanson, F.; Garrelie, F. Surface enhanced Raman spectroscopy platform based on graphene with one-year stability. Thin Solid Films 2016, 604, 74-80. [CrossRef]

28. Schiros, T.; Nordlund, D.; Pálová, L.; Prezzi, D.; Zhao, L.; Kim, K.S.; Wurstbauer, U.; Gutiérrez, C.; Delongchamp, D.; Jaye, C.; et al. Connecting dopant bond type with electronic structure in N-doped graphene. Nano Lett. 2012, 12, 4025-4031. [CrossRef] [PubMed]

29. Wu, O.; Du, P.; Zhang, H.; Cai, C. Microscopic effects of the bonding configuration of nitrogen-doped graphene and its reactivity toward hydrogen peroxide reduction reaction. Phys. Chem. Chem. Phys. 2013, 15, 6920-6928. [CrossRef] [PubMed]

30. Marsden, A.J.; Brommer, P.; Mudd, J.J.; Dyson, M.A.; Cook, R.; Asensio, M.-C.; Avila, J.; Levy, A.; Sloan, J.; Quigley, D.; et al. Effect of oxygen and nitrogen functionalization on the physical and electronic structure of graphene. Nano Res. 2015, 8, 2620-2635. [CrossRef] 